\title{
CLINICO-AETIOLOGICAL PROFILE OF NEONATAL SEIZURES AND THEIR OUTCOMES IN A TERTIARY CARE HOSPITAL
}

\author{
Menni Chowdary Babu1, B. S. Chakravarty2, N. Chaitanya ${ }^{3}$
}

${ }_{1}^{1}$ Associate Professor, Department of Paediatrics, King George Hospital, Andhra Medical College, Vishakapatnam, Andhra Pradesh. ${ }^{2}$ Associate Professor, Department of Paediatrics, King George Hospital, Andhra Medical College, Vishakapatnam, Andhra Pradesh. ${ }^{3}$ Senior Resident, Department of Paediatrics, King George Hospital, Andhra Medical College, Vishakapatnam, Andhra Pradesh.

\section{ABSTRACT}

\section{BACKGROUND}

Neonatal seizures defined as seizures occurring in first 28 days of life are one of the most common morbidity factors of admission in NICU. Incidence is 1.5 - 14/ 1000 neonates. Seizures often signify serious damage or malfunction of the immature developing central nervous system and contribute to sequelae in later life. Neonatal seizures may arise as a result of diverse aetiologies and can have varied presentations.

Aims and Objectives- Our study is aimed at finding the incidence, aetiological factors and time of onset, clinical types and various biochemical abnormalities and outcome of babies admitted with seizures in our NICU.

\section{MATERIALS AND METHODS}

It is a prospective observational study for a period of one year, i.e. from July 2015 to Aug 2016, carried out in the Department of Paediatrics, Andhra Medical College and King George Hospital, Visakhapatnam, Andhra Pradesh. A total of 150 neonates with neonatal seizures who fulfilled the inclusion criteria were included in the study.

\section{RESULTS}

During the study period a total no. of 150 babies were admitted with neonatal seizures in our NICU, of which males were 91 $(60.67 \%)$ and females were 59 (39.33\%). Most of the babies with seizures were admitted within 24 hrs. of life, i.e. 77 (51.33\%) followed by $48-72 \mathrm{hrs} .31$ (20.67\%) and the rest after $72 \mathrm{hrs}$. by 28 days 42 (28\%). Commonest type of seizures observed were focal clonic seizures 59 (39.33\%) followed by subtle 43 (28.66), myoclonic 27 (18\%), tonic 10 (6\%), multifocal 6 (4\%) and GTCS 5 (35). Among the various aetiological causes of seizures, HIE is the commonest cause 79 (52.67\%) followed by ICH 20 (13.33\%), meningitis 18 (12\%), hypoglycaemia 17 (11.33\%), hypocalcaemia 12 (8\%), hypomagnesaemia 5 (3.33\%) and others 9 (6\%). Commonest organism isolated was E. coli $44.5 \%$. The total neonatal mortality rate of babies admitted with seizures was 12 (8\%), of which HIE is the commonest cause $6(50 \%)$ followed by ICH $3(25 \%)$ and others $3(25 \%)$.

\section{CONCLUSION}

The present study shows that perinatal asphyxia is the most common cause of neonatal seizures among neonates admitted for seizures in our NICU. The other causes followed in order are IVH, sepsis, metabolic (hypoglycaemia, hypocalcaemia) and brain malformations. Early identification of at-risk pregnancies, institutional delivery and aseptic precautions with timely resuscitation is recommended to reduce morbidity and mortality due to neonatal seizures.

\section{KEYWORDS}

Neonatal Seizures, Clinical Profile, Aetiology and Outcomes.

HOW TO CITE THIS ARTICLE: Babu MC, Chakravarty BS, Chaitanya N. Clinico-aetiological profile of neonatal seizures and their outcomes in a tertiary care hospital. J. Evolution Med. Dent. Sci. 2018;7(15):1888-1891, DOI: 10.14260/jemds/2018/425

\section{BACKGROUND}

Neonatal seizures are a common neurological problem in neonates with a frequency of $1.5-14 / 1,000$ neonates.[1] A seizure is defined as paroxysmal electrical discharge from brain which may manifest as motor, sensory, behavioural or autonomic dysfunctions.[2] Neonatal seizures are clinically significant, as they may be symptomatic of an underlying disorder or primary epileptic condition. The occurrence of seizure may be the first indication of neurological disorder and the time of onset of seizure has relationship with the

'Financial or Other Competing Interest': None.

Submission 27-01-2018, Peer Review 25-03-2018,

Acceptance 31-03-2018, Published 09-04-2018.

Corresponding Author:

Dr. B. S. Chakravarty,

Associate Professor, Department of Paediatrics,

King George Hospital, Andhra Medical College,

Vishakapatnam, Andhra Pradesh.

E-mail: chowdarymenni99@gmail.com

DOI: $10.14260 /$ jemds $/ 2018 / 425$

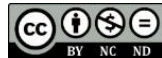

aetiology of seizures and prognosis. Common causes of convulsions in new born are hypoxic ischaemic encephalopathy (HIE), cerebral infarction and stroke, intracranial haemorrhage, intracranial infections, metabolic disturbances and undetermined.[3,4] Biochemical disturbances occur frequently in neonatal seizures either as an underlying cause or as associated abnormalities and are often underdiagnosed. Early recognition and treatment of these biochemical disturbances are essential for optimal management and satisfactory long-term outcome. More importance should be given to look for metabolic abnormalities and do biochemical workup in every case of neonatal seizures. This study is designed to determine biochemical abnormalities in relation to clinical presentation, which would help with early recognition and treatment and hence better prognosis in neonatal seizures.

\section{MATERIALS AND METHODS}

It is a prospective observational study done in Department of Paediatrics, Andhra Medical College, King George Hospital, 
Visakhapatnam, Andhra Pradesh for a period of one year, i.e. from July 2015 to Aug 2016. This study was approved by Institutional Ethical Committee and written consent was obtained from parents of the studied neonates.

The aim of our study is to find out the incidence, aetiological factors and time of onset, clinical types and various biochemical abnormalities and outcome of babies admitted with seizures in our NICU.

\section{Inclusion Criteria}

- Detailed and unequivocal description of neonatal seizures by the mother and attending doctor.

- Occurrence of first seizure up to 28 days of life.

\section{Exclusion Criteria}

- Uncertain clinical manifestations, i.e. Jitteriness.

- Those who had first seizure $>28$ days.

Detailed antenatal history i.e. maternal age, past medical history, parity, gestational age, history of illness during pregnancy, medication during pregnancy; natal history viz. evidence of foetal distress, Apgar score, type of delivery and medication given to mother during delivery were recorded. Baseline characteristics of convulsing neonate including sex, gestational age, weight, head circumference and length were recorded at admission. Clinical details of each seizure episode were recorded i.e. age at onset of seizures, duration of seizure and number and type of seizure. Seizures were classified into subtle, focal clonic, multifocal clonic, tonic and myoclonic as per criteria by Volpe. Before instituting specific treatment blood glucose, total serum calcium levels, $\mathrm{Na}+\mathrm{K}+, \mathrm{Mg}$ and $\mathrm{P}-$ levels were determined.

Criteria for diagnosing various biochemical abnormalities:

Hypoglycaemia: Blood sugar $<40 \mathrm{mg} / \mathrm{dL}$ (Normal range 40-150 mg/dL).

Hypocalcaemia: Total serum calcium $<7 \mathrm{mg} / \mathrm{dL}$ (Normal range $7-10 \mathrm{mg} / \mathrm{dL}$ ) or ionised calcium $<4 \mathrm{mg} / \mathrm{dL}$ (Normal range $4-5.5 \mathrm{mg} / \mathrm{dL}$ ).

Hypomagnesaemia: Serum magnesium $<1.5 \mathrm{mg} / \mathrm{dL}$ (Normal range: $1.5-1.8 \mathrm{mg} / \mathrm{dL}$ ).

Hypernatraemia: Serum sodium $>150 \mathrm{mEq} / \mathrm{dL}$ (Normal range $130-150 \mathrm{mEq} / \mathrm{dL}$ ).

Hyponatraemia: Serum sodium $<130 \mathrm{mEq} / \mathrm{dL}$.

Hypokalaemia: Serum potassium $<3.5 \mathrm{mEq} / \mathrm{dL}$ (Normal range $3.5-5.5 \mathrm{mEq} / \mathrm{dL}$ ).

Hyperkalaemia: Serum potassium $>5.5 \mathrm{mEq} / \mathrm{dL}$.

Hyperphosphataemia: Serum phosphorus $>8 \mathrm{mg} / \mathrm{dL}$ (Normal range 6 - $8 \mathrm{mg} / \mathrm{dL}$ ).

In addition, complete blood counts, band cell count, absolute neutrophil count, micro-ESR, blood culture, USG cranium, MRI/CT and CSF analysis were done as per the requirement in individual cases.

\section{Statistical Analysis}

Data was described as mean $\pm \mathrm{SE}$ and \%age. Software used for data analysis was SPSS 16.0 (Statistical Package for Social Sciences) and MS Excel.

\section{RESULTS}

Present study was conducted in the Department of Paediatrics NICU, King George Hospital from July 2015 to
August 2016. A total of 150 neonates with neonatal seizures, who fulfilled the inclusion criteria were included in the study.

Gender: Of the 150 neonates studied 91 were males and 59 were females.

\begin{tabular}{|c|c|c|}
\hline Gender & Number of Patients & \% Contribution \\
\hline Males & 91 & 60.67 \\
\hline Females & 59 & 39.33 \\
\hline \multicolumn{3}{|c|}{ Table 1. Gender Distribution } \\
\hline
\end{tabular}

\section{GENDER DISTRIBUTION}

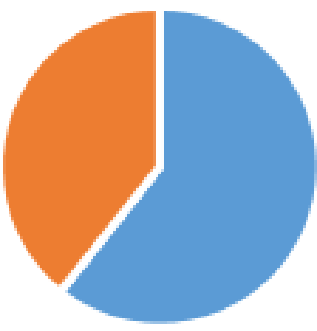

- MALES - FEMALES

\begin{tabular}{|c|c|}
\hline Age at Onset of Seizure & \% Distribution \\
\hline$\leq 24 \mathrm{hrs}$. & $51.33 \%$ \\
\hline $48-72 \mathrm{hrs}$. & $20.67 \%$ \\
\hline $72 \mathrm{hrs} .-1 \mathrm{wk}$ & $14 \%$ \\
\hline$>1 \mathrm{wk}$ & $14 \%$ \\
\hline \multicolumn{2}{|c|}{ Table 2. Age of Onset of Seizures } \\
\hline
\end{tabular}

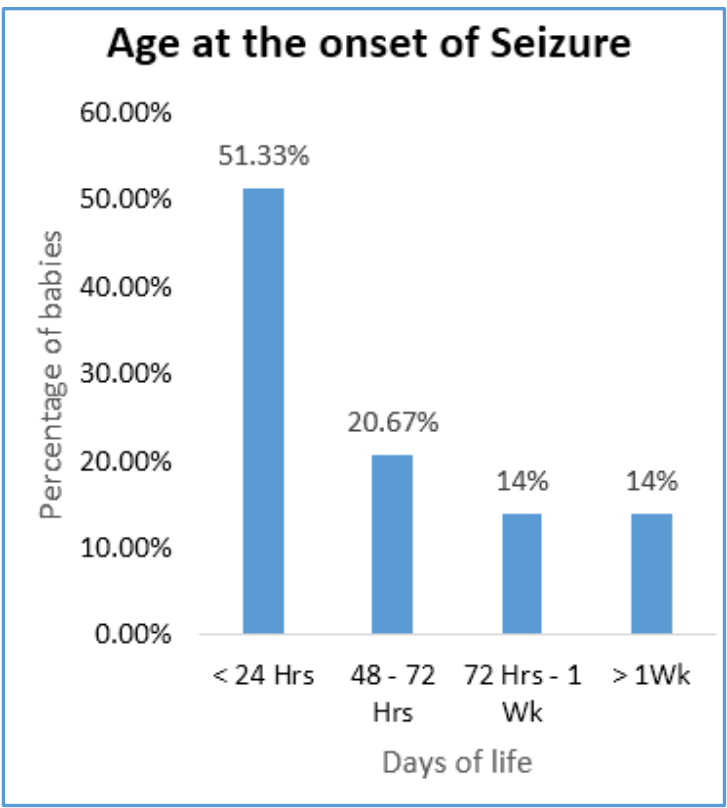

\begin{tabular}{|c|c|c|}
\hline Name & Number & Percentage \\
\hline Focal & 59 & 39.33 \\
\hline Subtle & 43 & 28.66 \\
\hline Myoclonic & 27 & 18.00 \\
\hline Tonic & 10 & 06.00 \\
\hline Multifocal & 6 & 04.00 \\
\hline GTCS & 5 & 03.00 \\
\hline Total Table 3. Type of Seizures \\
\hline \multicolumn{3}{|c|}{} \\
\hline
\end{tabular}




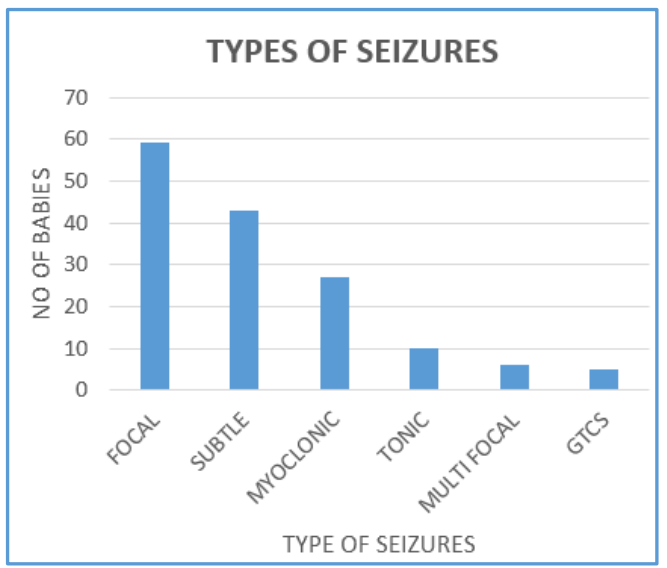

\begin{tabular}{|c|c|c|}
\hline Cause & Number of Cases & \% Distribution \\
\hline HIE & 79 & 52.67 \\
\hline ICH & 20 & 13.33 \\
\hline Meningitis & 18 & 12 \\
\hline Hypoglycaemia & 17 & 11.33 \\
\hline Hypocalcaemia & 12 & 8 \\
\hline Hypomagnesaemia & 5 & 3.33 \\
\hline Others & 9 & 6 \\
\hline \multicolumn{2}{|c|}{ Table 4. Aetiology of Neonatal Seizures } \\
\hline
\end{tabular}

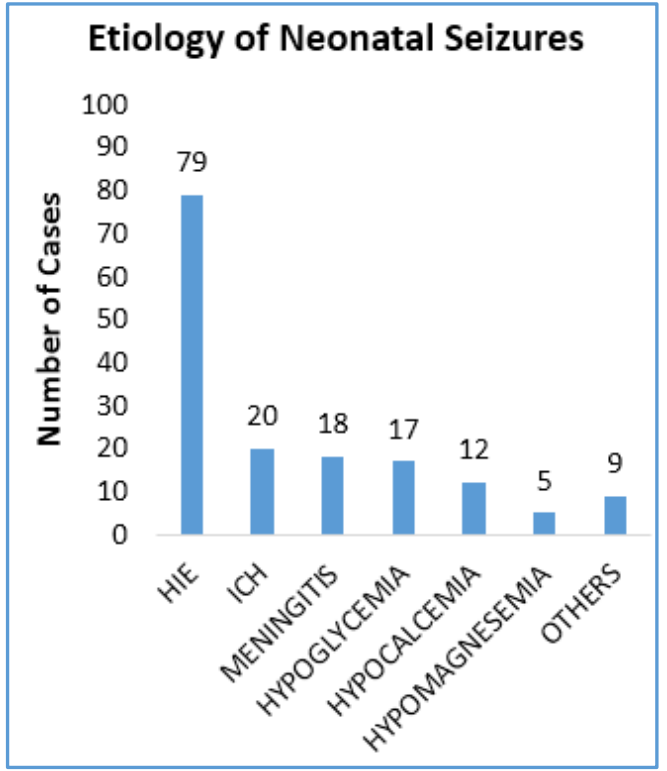

\begin{tabular}{|c|c|}
\hline Organism & \% Distribution \\
\hline E. coli & $44.45 \%$ \\
\hline Klebsiella & $33.33 \%$ \\
\hline Staph. aureus & $22.22 \%$ \\
\hline \multicolumn{2}{|c|}{ Table 5. Organisms causing Seizures } \\
\hline
\end{tabular}

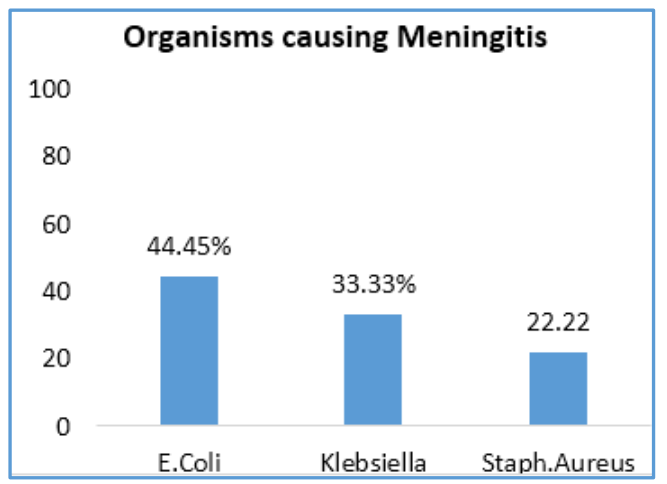

\begin{tabular}{|c|c|c|}
\hline Cause & Live & Death \\
\hline HIE & $48.67 \%$ & $4 \%$ \\
\hline ICH & $11.33 \%$ & $2 \%$ \\
\hline Meningitis & $10.67 \%$ & $1.33 \%$ \\
\hline Hypoglycaemia & $11.33 \%$ & $0 \%$ \\
\hline Hypocalcaemia & $8 \%$ & $0 \%$ \\
\hline Hypomagnesaemia & $3.33 \%$ & $0 \%$ \\
\hline Others & $5.33 \%$ & $0.67 \%$ \\
\hline \multicolumn{2}{|c|}{ Table 6. Outcomes of Aetiologies } \\
\hline
\end{tabular}

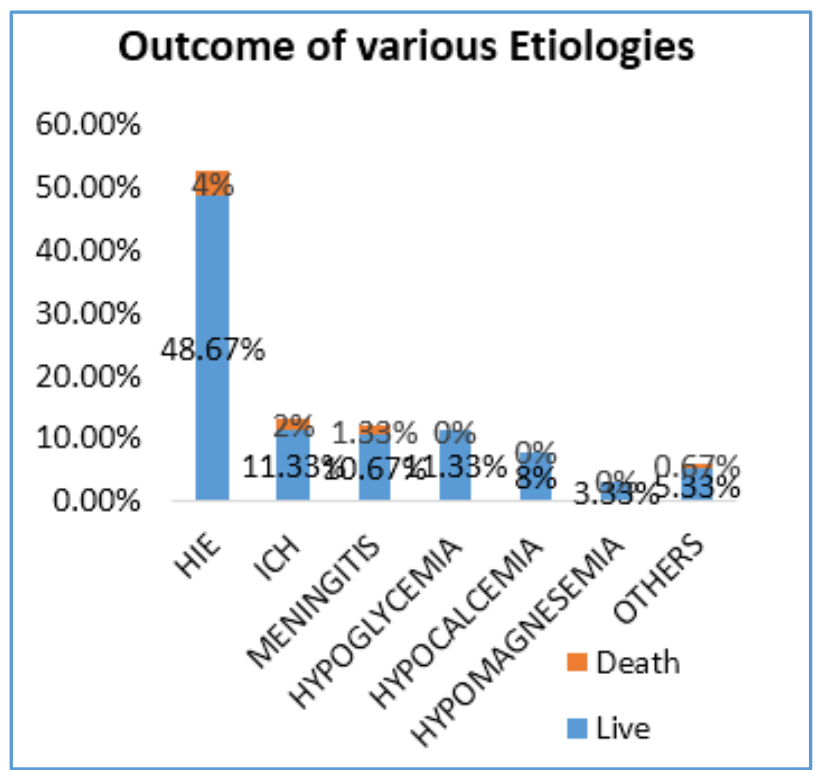

\section{RESULTS}

During the study period from July 2015 to Aug 2016 a total no. of 150 babies were admitted with neonatal seizures in our NICU, of which males were $91(60.67 \%)$ and females were 59 (39.33\%). Most of the babies with seizures were admitted within 24 hrs. of life, i.e. 77 (51.33\%) followed by 48 - 72 hrs. $31(20.67 \%)$ and the rest after 72 hrs. to 28 days $42(28 \%)$. Commonest type of seizures observed were focal clonic seizures 59 (39.33\%) followed by subtle 43 (28.66), myoclonic $27(18 \%)$, tonic $10(6 \%)$, multifocal $6(4 \%)$ and GTCS 5 (35). Among the various causes of seizures, HIE is the commonest cause 79 (52.67\%) followed by ICH 20 (13.33\%), meningitis 18 (12\%), hypoglycaemia 17 (11.33\%), hypocalcaemia 12 (8\%), hypomagnesaemia 5 (3.33\%) and others 9 (6\%). Commonest organism isolated was E. coli $44.5 \%$. The total neonatal mortality rate of babies admitted with seizures was $12(8 \%)$, of which HIE is the commonest cause $6(50 \%)$ followed by ICH 3 (25\%) and others 3 (25\%).

\section{DISCUSSION}

Neonatal seizures typically signal underlying significant neurological disease. Seizures occurring during neonatal period are unique, because of close relation to the perinatal events and their incidence being a reflection of quality of perinatal and neonatal care. The recognition of aetiology is often helpful with respect to prognosis and management. Biochemical disturbances and meningitis occur frequently in neonatal seizure either as an underlying cause or as an associated abnormality. In their presence, it is difficult to control seizures and there is risk of further brain damage.

The present study was conducted on neonates with seizures admitted to Neonatology unit of King George 
Hospital, Visakhapatnam during the study period from July 2015 to August 2016.

150 neonates had seizures during this study period, out of which 91 (61.67\%) were males and 59 (39.33\%) were females. Several series of neonatal seizures (Keen 1969, Cockburn 1973, Knauss 1977, Holden 1982 and Bergman 1983) showed a male preponderance. These findings are similar to the studies done by Sahana G et al, Sabzehei MK et al, Parvin R et al and Moayedi AR et al.[5,6]

Of the 150 neonates with seizures, 77 (51.33\%) had seizures on Day 1 followed by 31 (20.67\%) within 48 - $72 \mathrm{hrs}$. and the rest after $72 \mathrm{hrs}$. to 28 days 42 (28\%) on Day 2 of life, $8(9.5 \%)$ on Day 3 and $10(11.9 \%)$ on Day $\geq 8$ days of life. Similar findings were found by Sahana $G$ et al and Ronen Gabriel et al.[7,8]

Based on clinical seizure types, commonest type of seizures observed were focal clonic seizures 59 (39.33\%) followed by subtle 43 (28.66), myoclonic 27 (18\%), tonic 10 (6\%), multifocal 6 (4\%) and GTCS 5 (35). This was found in concordance with the study done by Aziz A et al and Verma YS et al..[9]

Perinatal asphyxia was the most common cause of neonatal seizures identified in 79 (52.67\%) 33.3\% of neonates. This was found to be in concordance with the study done by Najeeb S et al (46\%), Sabzehei MK et al (34\%), Glass HC et al (38\%) and Malik BA et al (35\%). In other studies done by Verma YS et al (70\%) of neonates had seizures due to hypoxic ischaemic encephalopathy.[10]

In the present study $12(18 \%)$ of 150 babies had sepsis (septicaemia and meningitis). This was found near similar to the study done by Parvin R et al $(26 \%, n=51)$, Sabzehei MK et al $(24.4 \% \mathrm{n}=102)$ and was found to be $(29 \%)$ by the study done by Najeeb S et al.[11]

Seizures due to hypoglycaemia in association with comorbidities like HIE, septicaemia and IDM were accounted for 17 (11.33\%). This was seen in concordance with the study done by Kumar A et al (11.11\%), Sahana G et al (9.17\%).5,7 Seizures due to hypocalcaemia were 12 (22.6\%) babies. This was also found similar to the study done by Parvin $\mathrm{R}$ et al $815.65 \%(n=51)$ and Taksande AM et al $(n=110)$ where they found to be $11.8 \%$ and Verma YS et al found it to be $11.67 \%$ $(\mathrm{n}=60) \cdot[12]$

Seizures due to ICH in our study was $20(13.33 \%)$ and this was similar to the study by Asif Aziz et al 13\% and Bushra et al 9.5\%. Incidence of intraventricular haemorrhage was much higher in preterm than term neonates. Ross et al and Scher MS et al also reported higher incidence of intraventricular haemorrhage in preterm.[13]

The total neonatal mortality rate of babies admitted with seizures was $12(8 \%)$, of which HIE is the commonest cause $6(50 \%)$ followed by ICH 3 (25\%) and others 3 (25\%). Mortality in our cohort is consistent with other cohort studies (e.g. $16 \%$ among term infants and $42 \%$ among premature infants in Ontario, Canada).[14]

\section{CONCLUSION}

The present study shows perinatal asphyxia is the most common cause of neonatal seizures among neonates admitted for seizures in our NICU. The other causes followed in order are IVH, sepsis, metabolic (Hypoglycaemia, Hypocalcaemia) and brain malformations. Overall focal clonic and subtle seizures were the commonest seizure types encountered, early identification of at risk pregnancies, institutional delivery and aseptic precautions with timely resuscitation are recommended to reduce morbidity and mortality due to neonatal seizures.

\section{REFERENCES}

[1] Airede KI. Neonatal seizures and a 2-year neurological outcome. J Trop Pediatr 1991;37(6):313-7.

[2] Mikati MA, Kliegman RM, Behrman RE, et al. Seizures in childhood; Nelson textbook of paediatrics. 19th edn. Philadelphia: WB Saunders, 2011:2013-7.

[3] Sankar MJ, Agarwal R, Aggarwal R, et al. Seizures in the newborn. Indian J Pediatr 2008;75(2):149-55.

[4] Volpe JJ. Neonatal seizures. In: Neurology of the newborn. $4^{\text {th }}$ edn. Philadelphia, PA: WB Saunders, 2001:178-214.

[5] Parvin R, Afmsalim, Rahman M, et al. Neonatal seizures: correlation between clinico-etiological profile and eeg findings. Bangladesh J Child Health 2014;38(1):19-23.

[6] Moayedi AR, Zakeri S, Moayedi F. Neonatal seizure: etiology and type. Iranian J Child Neurol 2008;2(2):236.

[7] Sahana G, Anjaiah B. Clinical profile of neonatal seizures. Int J Med Appl Sci 2014;3(1):21-7.

[8] Ronen GM, Rosales TO, Connolly M, et al. Seizure characteristics in chromosome 20 benign familial neonatal convulsions. Neurology 1993;43(7):1355-60.

[9] Aziz A, Gattoo I, Aziz M, et al. Clinical and etiological profile of neonatal seizures: a tertiary care hospital based study. Int J Res Med Sci 2015;3(9):2198-203.

[10] Verma YS, Dutt R, Rajput N, et al. Predictive value of EEG for neurodevelopmental outcome in neonatal seizures. J Evol Med Dent Sci 2013;2(29):5417-25.

[11] Najeeb S, Qureshi AM, Anis-ur-Rehman, et al. Aetiology and types of neonatal seizures presenting at Ayub teaching hospital Abbottabad. J Ayub Med Coll Abbottabad 2012;24(1):33-7.

[12] Taksande AM, Krishna V, Jain M, et al. Clinicobiochemical profile of neonatal seizures. Paed Oncall J 2005;2(10).

[13] Glass HC, Shellhaas RA, Wusthoff CJ, et al. Contemporary profile of seizures in neonates: a prospective cohort study. J Pediatr 2016;174:98-103.

[14] Ronen GM, Buckley D, Penney S, et al. Long-term prognosis in children with neonatal seizures: a population-based study. Neurology 2007;69(19):1816-22. 